\title{
Interferon system in acute transient synovitis
}

\author{
E LEIBOWITZ, S LEVIN, J TORTEN, AND R MEYER
}

Paediatric Department $A$ and Paediatric Research Institute, Kaplan Hospital, Rehovot, Israel

SUMmARY The interferon system of 20 children aged 2 to 11 years (mean 5 years), diagnosed as having transient synovitis of the hip by clinical criteria, was studied. The mean blood interferon concentration was significantly higher than that of normal children, and the incidence of an antiviral state of cells (in $78 \%$ of patients) was also significantly higher than in the control group. These findings are compatible with the hypothesis that the aetiology of transient synovitis is an acute, possibly unusual, viral infection.

Transient synovitis of the hip (or irritable hip) is probably the most common hip disorder causing pain and limp in young children. It is usually a self limiting condition, and occurs mainly between the ages of 2 and 12 years, most commonly in boys.

A history of a preceding upper respiratory disease (34 to $65 \%$ ), usually viral in aetiology, has often been reported. ${ }^{1-3}$ Several studies of children with transient synovitis of the hip, however, have failed to establish any association with infections by bacteria (including staphylococci, streptococci) or viruses, or with allergies or trauma. ${ }^{4-7}$

The immune mechanisms for controlling and combating viral infections are complex and not yet completely understood, but it is clear that the interferon system plays an important part in the defence against viral infections and the prevention of clinical disease. The interferons are a group of cytokines that are produced by various body cells after stimulation with viruses, mitogens, antigens, and some other organisms. ${ }^{8}$ Viruses seem to be the most potent inducers of interferon, and interferon values become raised within hours of the occurrence of viraemia. A major function of interferon is to prevent further replication of viruses in cells, and its importance therefore is in its very early production, after viral infection is established. After production by stimulated cells, these interferons act as biological messengers whose purpose is to activate a broad spectrum of biological activities necessary for the proper functioning of the immune system. ${ }^{89}$

Over the past few years we have developed a series of assays that evaluate in vivo and in vitro the integrity of the interferon system, and have used them in the study of a large series of subjects of all ages, in health and disease. ${ }^{9}$ These assays test in vivo interferon production, and induction of an antiviral state in peripheral blood mononuclear cells, as well as in vitro production of interferon $\alpha$ and $\gamma$ by these cells. ${ }^{10}$

In this study we looked for an activated interferon system (as commonly found in viral infections) as secondary or circumstantial evidence for a viral aetiology in transient synovitis of the hip.

\section{Material and methods}

Twenty children had transient synovitis of the hip diagnosed in this hospital during 1983-4, 18 of whom were admitted to hospital and two treated in the outpatient clinic. All patients were seen by our orthopaedic consultants, and fulfilled the following diagnostic criteria:

Sudden development of pain in the hip or thigh;

Restricted range of joint movement;

Limp or loss of ability to bear weight on the affected limb;

Normal radiographic appearance;

Resolution after short term bed rest with skin traction, but without specific treatment;

Absence of any obvious or specific cause for the symptoms.

The controls were 74 healthy subjects of all ages and both sexes whose blood had been assayed over the past few years, including the period of the present study. We have not found any significant differences in the interferon systems of persons of different ages, including newborns, or differences between the sexes.

Interferon system assays. These assays have previously been described in detail. ${ }^{10}$ In brief, hepari'nised blood $(15 \mathrm{ml})$ was drawn, and the mononuclear cells were separated on a Ficoll-Paque gradient. 
Interferon blood concentrations. These were assayed in plasma on the day of sampling. An ELISA assay was performed using antiserum to vesicular stomatitis virus for quantitating residual viral protein after infection of $\mathrm{H} 229$ cells that had been pretreated with serial dilutions of the patient's serum. Results were designated as IU/ml using the International IFN Standard BRS 69/19 for comparison.

In vitro production of interferon $\alpha$ and $\gamma$ by peripheral blood mononuclear cells. After separation of peripheral mononuclear cells on a FicollPaque gradient, the cells were stimulated with phytohaemagglutinin to induce production of interferon $\gamma$, and with poly-inosinic-cytidilic acid for interferon $\alpha$ production. The supernatants from these experiments together with supernatants of a control parallel assay using unstimulated peripheral blood mononuclear cells, were tested for interferon content as described above.

Assay of the antiviral state of peripheral blood mononuclear cells. This was assayed by measuring the replicating efficiency of vesicular stomatitis virus in peripheral blood mononuclear cells. Peripheral blood mononuclear cells $\left(10^{5}\right)$ were infected with a median tissue culture infective dose $\left(10^{3}\right)$ of vesicular stomatitis virus. The resulting virus yield was assayed after 48 hours by examining the cytopathogenic effect after the addition of 10 fold dilutions of vesicular stomatitis virus-infected peripheral blood mononuclear cell supernatants to indicator fibroblast monolayers, or by measuring the amount of viral protein remaining in culture. A virus yield greater than the original infecting dose indicated viral replication and absence of an antiviral state in the peripheral mononuclear cells examined. Our studies have shown that lymphocytes do not need to be in a stimulated state in order to support viral replication, and that good correlation exists between increased concentrations of interferon in the blood (more than $16 \mathrm{IU} / \mathrm{ml}$ ) and the presence of an antiviral state (less than $10^{3}$ median tissue culture infective dose viral yield) in the peripheral blood mononuclear cells.

Statistical analysis. Statistical analysis was by the Student's $t$ test and $\chi^{2}$ test.

\section{Results}

The average age of the patients was 5.3 years, and more boys (13) had the disorder than girls (7). The right hip was affected in 14 patients $(70 \%)$. Trauma or allergy was not associated with any case, and only three children reported an upper respiratory tract infection before onset of the illness. Six (30\%) of the children had had a previous episode of transient synovitis (in the same or opposite hip).

The period of time from the onset of symptoms to hospital admission was usually short, and in only four patients were symptoms present for more then three days beforehand. Two patients had mild symptoms for six to eight weeks, with exacerbation before hospital admission, but their disease was not more severe nor was the period spent in hospital longer than in the other children. No complications developed after recovery.

All of the patients complained of pain in the hip or thigh and all had a limp with restriction of hip movements. The duration of the acute illness ranged from 4 to 20 days with a mean of $7 \cdot 5$ days. The average stay in hospital was 4.5 days with a range of 2 to 12 days. A raised temperature at admission was uncommon; no patient had a temperature greater than $38^{\circ} \mathrm{C}$ at this time. Sixteen patients had their erythrocyte sedimentation rate determined on admission, and the mean rate in the first hour was $15 \mathrm{~mm}$ with a range of 5 to $40 \mathrm{~mm}$; only two of them had a reading above $30 \mathrm{~mm}$ after one hour. Blood counts were determined in all patients on admission, and the mean leukocyte count was $1 \times 10^{10} / 1$ with a range of $5-16 \times 10^{9} / 1$. No eosinophilia was noted in our patients. Radiological examinations of the hips were performed in all cases and none showed any important abnormalities.

Treatment was standardised and consisted of bed rest, prevention of weight bearing, and skin traction. No patient had a diagnostic aspiration of the hip performed and none received antibiotics. All the patients improved clinically within a few days, and no complications were noted. Aseptic necrosis of the hip did not develop during follow up, which was six months or longer.

The results of the interferon system assays can be seen in the Table. Healthy controls are constantly examined in our laboratory and have been found to have virtually no interferon in their blood (with a mean of $5 \mathrm{IU} / \mathrm{ml}$ ), and in only $13 \%$ were their cells in an antiviral state. The blood interferon concentration in the patient group was mean (SD), 24 (40) IU $/ \mathrm{ml}$, significantly higher $(\mathrm{P}<0.05)$ than in the control group, and $8(40 \%)$ had concentrations greater than $16 \mathrm{IU} / \mathrm{ml}$. Two children had very high interferon concentrations (126 and $139 \mathrm{IU} / \mathrm{ml})$, but the clinical course of their disease was no different in any aspect from that of the other children. Eighteen of the 20 patients had assays performed to see whether their peripheral blood mononuclear cells would support viral replication in vitro, and 14 of them were found to have cells in an antiviral state. Seven $(58 \%)$ of the 12 patients with normal serum 
Table Interferon (IFN) production and protection assay in 20 patients with transient synovitis of the hip presenting between 1983 and 1984

\begin{tabular}{|c|c|c|c|c|c|}
\hline \multirow[t]{3}{*}{ Groups } & \multicolumn{4}{|c|}{ Production of interferon $(I U / m l)$, mean $(S D)$} & \multirow{3}{*}{$\begin{array}{l}\text { Antiviral } \\
\text { state } \\
\text { of cells* } \\
\left(<10^{3}\right)\end{array}$} \\
\hline & \multirow[t]{2}{*}{ In vivo } & \multicolumn{3}{|c|}{ In vitro (by $P B M C$ ) } & \\
\hline & & $\begin{array}{l}\text { Spontaneous } \\
\text { (non-stimulated) }\end{array}$ & $I F N \alpha$ & $I F N \gamma$ & \\
\hline $\begin{array}{l}\text { Healthy controls }(n=74) \\
\text { Patients }(n=20) \\
\text { Significance }(t \text { test })\end{array}$ & $\begin{array}{r}5(12) \\
24(40) \\
P<0.05\end{array}$ & $\begin{array}{l}2(5) \\
12(30) \\
P<0 \cdot 2\end{array}$ & $\begin{array}{l}382(519) \\
307(361) \\
\text { ns }(P>0 \cdot 2)\end{array}$ & $\begin{array}{l}170(200) \\
130(183) \\
\text { ns }(P>0 \cdot 2)\end{array}$ & $\begin{array}{l}13 \%(10 / 74) \\
78 \%(14 / 18) \\
P<0 \cdot 001\left(\chi^{2}\right)\end{array}$ \\
\hline
\end{tabular}

PBMC=peripheral blood mononuclear cells; $n s=$ not significant; $n=$ number of individuals tested.

*Antiviral state is present when $<10^{3}$ virus is present in PBMC 48 hours after culture of cells with $10^{3}$ vesicular stomatitis virus.

interferon values (less than $16 \mathrm{IU} / \mathrm{ml}$ ) had peripheral blood mononuclear cells in an antiviral state, possibly due to a very recent increased interferon concentration. Only four patients had normal serum interferon values: peripheral mononuclear cells were not in an antiviral state in these four. Blood interferon concentrations were significantly higher $(\mathrm{P}<0.02)$ in boys, in the older children, and in those patients with an erythrocyte sedimentation rate below $20 \mathrm{~mm}$ in the first hour.

In summary, 16 children $(80 \%)$ had either raised concentrations of interferon or an antiviral state of cells, or both, and this finding is similar to that in patients with viral infections. There was no significant difference between in vitro interferon $\alpha$ and $\gamma$ production by stimulated peripheral blood mononuclear cells in the patients when compared with that of healthy controls. Spontaneous production of interferon occurred in eight children $(40 \%)$, usually in low titres, but this was not significantly different from that recorded in healthy controls. No correlation was found between the interferon concentrations or the antiviral state of cells and age, sex, temperature, erythrocyte sedimentation rate, or blood count of the patients.

\section{Discussion}

The first report of the syndrome of transient synovitis was in 1892 when it was described as a form of hip disease that resembled tuberculosis and whose symptoms lasted for only a few weeks. Many unsuccessful attempts have been made since then to determine the aetiology of the condition, and infection, trauma, and allergy have been the most common possible causes mentioned. Spock described a definite correlation between the onset of transient synovitis and a recent infection of the respiratory tract, but found evidence of streptococcal disease in only $8 \%$ of his patients. ${ }^{3}$ Other studies failed to find the same correlation. In a virological study of 17 children with transient synovitis of the hip, Blockey and Porter found a rise in antibody titres in only two patients-one to adenovirus and one to parainfluenza. ${ }^{4}$ Hardinge studied the aetiological factors associated with transient synovitis in 65 patients and failed to establish any association with bacterial or viral infection, allergy or trauma. ${ }^{6}$

The universal antiviral properties of the interferons and the study of their concentrations in blood as an aid in diagnosing viral infections are well established. ${ }^{9}$ The antiviral interferon response is a two phased mechanism. In phase 1 a virus enters a cell where it replicates and at the same time sets in motion a series of intracellular events leading to the production of interferon molecules, which are rapidly released from the cell. ${ }^{8}$ In phase 2 , these molecules attach to receptors on other cells, again setting in motion a series of events that leads to the priming of an antiviral state in these cells. This occurs by stimulating the production in the cell of at least three antiviral proteins or enzymes whose functions, when later activated by the entry of a virus into this cell, are to prevent the transcription, translation, and assembly of new viruses from the infectious virus. Theoretically, this should put an end to the viral spread.

In normal healthy subjects, blood interferon concentrations are not usually measurable, and are less than $16 \mathrm{IU} / \mathrm{ml}$ in $95 \%$ of those examined. In $87 \%$ of healthy persons the peripheral blood mononuclear cells are not in an antiviral state. ${ }^{10}$ Studies of the interferon system in children and adults with various viral diseases showed significantly raised blood interferon concentrations and considerable in vitro inhibition of viral replication in their peripheral blood mononuclear cells. ${ }^{10}$ In this study we found that $40 \%$ of our children with transient synovitis had raised interferon values in serum. All 
the patients with raised concentrations had peripheral blood mononuclear cells in an antiviral state, and a further six patients with normal serum values also had peripheral blood mononuclear cells in an antiviral state. This finding is not surprising, since interferon has a short half life (four hours or less), and the presence of low concentrations may not always be a true indication of a defective response in patients with viral illnesses, whereas high values obviously have significance. The antiviral state of cells is of much longer duration and may be present in the peripheral blood mononuclear cell for several days after induction by interferon. Our results show that in most patients with transient synovitis there is an activated interferon system. As previous studies have shown that increased blood interferon concentrations and the development of an antiviral state in cells are the usual findings in acute viral illnesses, and are rare in normal, healthy persons, these findings suggest the possibility that the aetiology of transient synovitis is an acute, possibly unusual, viral infection, the causative agent of which has as yet not been identified. A similar picture has been reported in patients with Bell's seventh nerve palsy. ${ }^{11}$

\section{References}

' Illingworth CM. 128 limping children with no fracture, sprain, or obvious cause. Clin Pediatr 1978;17:139-42.

2 Jacobs BW. Synovitis of the hip in children and its significance. Pediatrics 1971;47:558.

${ }^{3}$ Spock A. Transient synovitis of the hip joint in children. Pediatrics 1959;24:1042.

${ }^{4}$ Blockey NY, Porter BB. Transient synovitis of hip. A virological investigation. $\mathrm{Br}$ Med J 1968;iv:557.

${ }^{5}$ Sherwood PF. The irritable hip syndrome in children. Acta Orthop Scand 1981:52:633-8.

${ }^{6}$ Hardinge K. The etiology of transient synovitis of the hip joint in childhood. J Bone Joint Surg 1970;52-B:100-7.

${ }^{7}$ Chung SMK. Hip disorders in infants and children. Philadelphia: Lea and Febiger, 1981.

${ }^{*}$ Levin S. Interferon in acute viral infections. Eur $J$ Pediatr 1983;140:2-4.

${ }^{9}$ Levin S, Hahn T. The interferon system in viral infections. Regulation of immune response. Basel: Karger, 1982.

10 Levin S, Hahn T. Evaluation of the human interferon system in viral disease. Clin Exp Immunol. 1981;46:475-83.

$"$ Aviel A, Hahn T, Levin S, Ostfeld E, Bregman V, Marshak G. Interferon anti-viral system in Bell's palsy. Acta Otolaryngol 1983;95:69-73.

Correspondence to Professor S Levin, Department of Paediatrics, Kaplan Hospital, POB 1 Rehovot, Israel.

Received 2 April 1985 